\title{
Intrauterine fetal demise-a tragic event: a study of its epidemiology, causes and methods of induction
}

\author{
Anupama Dave ${ }^{1 *}$, Ranjana Patidar $^{1}$, Sonam Goyal $^{1}$, Atisha Dave
}

\author{
${ }^{1}$ MGM Medical College Indore MP, India \\ ${ }^{2}$ Sri Aurobindo Institute of Medical Sciences, Indore, MP, India
}

Received: 20 March 2016

Accepted: 11 April 2016

\section{* Correspondence:}

Dr. Anupama Dave,

E-mail: anupamadave10@gmail.com

Copyright: (C) the author(s), publisher and licensee Medip Academy. This is an open-access article distributed under the terms of the Creative Commons Attribution Non-Commercial License, which permits unrestricted non-commercial use, distribution, and reproduction in any medium, provided the original work is properly cited.

\section{ABSTRACT}

Background: Fetal death is a tragedy that causes severe distress to parents and caregivers. Most babies are born healthy, but sometimes, something goes wrong and a baby dies in utero. Present study was conducted to understand the incidence, epidemiological and etiological factors of intrauterine fetal death. Also to study the efficacy of misoprostol and dinoprostone as inducing agents in these cases.

Methods: Present study was conducted in the Department of Obstetrics \&Gynaecology, M.G.M. Medical College and Associated M.Y. Group of Hospitals, Indore (MP). Pregnancies diagnosed with IUFD were studied from March 2014 to February 2015. A total of 200 cases were studied. Ante partum events leading to fetal demise were recorded, sociodemographic and clinical characters were noted. Induction delivery interval of inducing agents was compared.

Results: Incidence of IUFD at our centre was found to be 50 per 1000 deliveries. There was a high incidence in low socioeconomic strata, unbooked cases, primigravidas, preterm with abruption were the leading causes. Misoprostol was found to be more effective in termination of pregnancy in these cases .The induction delivery interval with Misoprostol was $9.64 \mathrm{hrs}$ and that of dinoprostone was $12.63 \mathrm{hrs}$.

Conclusions: Socio- demographic factors like poor socioeconomic class, teenage pregnancy, poor nutrition, lack of health education need to be considered as predisposing factor for prenatal deaths, many of the causes of intrauterine deaths are preventable like abruption hypertensive disorders which can be avoided by proper antenatal care. Misoprostol is cheaper and has a less induction delivery interval; it can be safely used in cases of IUFD.

Keywords: Intrauterine fetal demise, IUFD, Dinoprostone, Misoprostol

\section{INTRODUCTION}

The transcendent objective of obstetrics is that every pregnancy be wanted \& that it culminates in a healthy mother \& a healthy baby. Pregnancy loss is a distressing problem for both the couple \& the obstetrician.

The loss of a fetus at any stage is a fetal demise. According to the 2003 revision of the Procedures for Coding Cause of Fetal Death Under ICD-10, the National Center for Health Statistics defines fetal death as "death prior to the complete expulsion or extraction from its mother of a product of human conception, irrespective of the duration of pregnancy and which is not an induced termination of pregnancy. ${ }^{1}$ The gestational age at which intrauterine fetal demise is considered a still birth varies from county to country. Some countries count demise at 16 weeks as IUFD while others consider fetal demise as late as 28 weeks as IUFD. In a recent RCPI (Recent clinical practice investigation guideline), stillbirth is taken as a baby delivered without signs of life from 24 weeks gestation and IUFD is taken to refer to death in utero after 24 weeks gestation. ${ }^{2}$ ACOG refers to IUFD as the demise occurring at or later than 20 weeks. ${ }^{3}$ 
In 2009 , the estimated global number of stillbirths was 2.64 million (uncertainty range, $2.14-3.82$ million). ${ }^{4}$ The worldwide stillbirth rate declined by $14.5 \%$ from 22.1 stillbirths per 1000 births in 1995 to 18.9 stillbirths per 1000 births in 2009. Range of incidence varies in different countries, ranging from 5 in 1000 births in high income countries and 36 in 1000 births in developing countries The still birth rates in India is 9 per thousand births, (9:1000 births in rural India and 8 in 1000 births urban India), according to the Indian census of 2006.5According to census 2010 the estimate of still birth rate for the year 2010, at the National level is 7 per 1000 .

Several maternal demographic factors are associated with an increased risk of intrauterine fetal demise. Higher rates of fetal death was observed in age group $>35$ yrs, weight $>85 \mathrm{~kg}$, unbooked cases not accessed to proper antenatal care, poor socioeconomic status. Several medical disorders like hypertension, diabetes, thyroid disease, kidney disease, asthma, thrombophilias are associated with intrauterine deaths.

Unexplained antepartum still births are now a major contributor to perinatal mortality in developed countries, whereas in developing Nation's preventable factors, asphyxia, infection, traumatic cerebral hemorrhage and intracranial damage from difficult labour and delivery are responsible for majority of still births. Maternal causes includes toxemia of pregnancy, uterine inertia, dry labour, acute or chronic febrille illness, cardiac diseases, $\mathrm{CPD}$, rupture uterus, trauma to mother, anaemia, oligohydramnios, postmaturity, polyhydramnios, PROM, hepatic encephalopathy, jaundice, Rh incompatibility, epilepsy, diabetes.

Fetal causes include breech, transverse lie, multiple pregnancy, congenital malformation, birth trauma, MSL, IUGR, hand prolapse. Placental causes include placenta previa, premature separation of placenta, coiling of umbilical card, hydramnios, prolapse of cord, true knot in umbilical cordand short cord.

After the detection of intrauterine death most women prefer to proceed with delivery of the fetus. It is emotionally stressful to carry a nonviable fetus, especially late in gestation. It is important to offer both the options of delivery and expectant management to women experiencing fetal death. The method and timing of delivery after a fetal death depends on the gestational age at which the death occurred, on the maternal history of a previous uterine scar and maternal preference. Prostaglandins are used for induction of labour in cases of IUFD; of which, misoprostol, a synthetic analogue of prostaglandins is widely used because of its low cost, stability at room temperature, long shelf life and ease of administration. Dinoprostone (PGE2) gel is also widely used for induction of labour in IUFD but it is expensive. Misoprostol can be used in preference to prostaglandin E2 because of equivalent safety and efficacy with lower cost. The Royal College of Obstetricians and
Gynaecologists' (RCOG) guideline on the management of late IUFD (after 24 completed weeks of pregnancy) and stillbirth advises that the dose of misoprostol should be adjusted according to gestational age (100 micrograms 6hourly before 26 weeks; 25 to 50 micrograms 4-hourly at 27 weeks or more.

The present study aims at studying the various socioeconomic causes related to IUD and the method of termination and to compare the efficacy of misoprostol and dinoprostone in induction.

\section{METHODS}

It was a prospective study conducted in the Department of Obstetrics \& Gynaecology, M.G.M. Medical College and Associated M.Y. Group of Hospitals, Indore (M.P.). All pregnancies diagnosed with IUFD in cases admitted in the Department were studied from March 2014 to February 2015. A total of 200 cases were studied.

\section{Selection criteria}

\section{Inclusion criteria}

All those cases who were diagnosed as intrauterine dead fetus at the time of admission with gestational age $>28$ weeks pregnancy were included in the study.

The method and timing of delivery after a fetal death depends on the gestational age at which the death occurred, on the maternal history of a previous uterine scar,

\section{Exclusion criteria}

All cases of intrapartum IUFD were excluded and all the cases $<28$ weeks were also excluded from the study.

Records were thoroughly analysed with respect to age, parity, gestational age, socioeconomic status, antenatal care, associated complicating factors like hypertensive disorders of pregnancy, diabetes, Rh isoimmunization, severe anaemia. Fetal characteristics were studied with respect to sex, birth weight, gross congenital anomalies. Risk factors related to placenta and cord (true knot, cord prolapse and tight cord around neck) were also analysed. Laboratory investigations were studied. Method of induction in these cases was studied and the efficacy of misoprostol was compared with dinoprostone in induction.

\section{Statistical analysis}

Unpaired t test was applied to determine the significance. It was done by SSPS version 20.1 


\section{RESULTS}

Total number of deliveries during this period was 10529 . Among this, total number of IUFD > 28 wks of gestation were 200. Incidence of IUFD at our centre was found to be 50 per 1000 deliveries. In our study that maximum number of still birth occurred between the age group of 21 to 25 years $(51 \%) .2^{\text {nd }}$ in the age group $26-29(14.5 \%)$.
Maximum numbers of cases studied were unbooked $(86.5 \%)$ as compared to $13.5 \%$ cases, which were booked. The IUFD occurred mainly in low socioeconiomic class V and IV (84\%) it was minimum in class I. Maximum number of intrauterine deaths occurred in primi $(44.5 \%)$ followed by second gravida $(37.5 \%) 3^{\text {rd }}$ gravida showed $10 \%$ still birth and in $4^{\text {th }}$ and $5^{\text {th }}$ gravida it was $7 \%$ respectively.

Table 1: Distribution of cases according to different demographic variables.

\begin{tabular}{|c|c|c|c|}
\hline Age in Years & Number of Still Birth & Percentage & Mean \pm SD \\
\hline $15-20$ & 27 & 13.5 & \multirow{4}{*}{25.04 years \pm 4.084} \\
\hline $21-25$ & 102 & 51 & \\
\hline $26-29$ & 29 & 14.5 & \\
\hline$>30$ & 42 & 21 & \\
\hline \multicolumn{4}{|l|}{ Parity } \\
\hline Primi & 89 & 44.5 & \multirow{5}{*}{$0.895 \mathrm{yrs}$} \\
\hline $2^{\text {nd }}$ & 75 & 37.5 & \\
\hline $3^{\text {rd }}$ & 20 & 10 & \\
\hline $4^{\text {th }}$ & 9 & 4.5 & \\
\hline $5^{\text {th }} \&$ above & 7 & 3.5 & \\
\hline \multicolumn{4}{|l|}{ Socioeconomic class } \\
\hline Socio economic class & Total number of cases & Percentage & Mean/frequency \\
\hline I & 04 & 2 & \\
\hline II & 10 & 5 & \\
\hline III & 18 & 9 & \\
\hline IV & 78 & 39 & \\
\hline V & 90 & 45 & \\
\hline \multicolumn{4}{|l|}{ Booked/ unbooked } \\
\hline Booked & 27 & 13.5 & \\
\hline Unbooked & 173 & 86.5 & \\
\hline
\end{tabular}

Table 2: Distribution of cases according to different variables of fetus.

\begin{tabular}{|c|c|c|c|}
\hline Sex & Total number of cases & Percentage & Mean /frequency \\
\hline Male & 122 & 61 & \\
\hline Female & 78 & 39 & \\
\hline \multicolumn{3}{|c|}{ Birth weight (grams) } & \multirow{7}{*}{$1.83175 \mathrm{~kg}+0.725$} \\
\hline $500-1000$ & 46 & 23 & \\
\hline $1001-1500$ & 38 & 19 & \\
\hline $1501-2000$ & 40 & 20 & \\
\hline $2001-2500$ & 45 & 22.5 & \\
\hline $2501-3000$ & 25 & 12.5 & \\
\hline $3001 \&$ Above & 6 & 3 & \\
\hline \multicolumn{3}{|c|}{ Gestational age (wks) } & \multirow{5}{*}{$33.455 \mathrm{yrs}$} \\
\hline 28-31 weeks & 72 & 36 & \\
\hline $32-36$ weeks & 75 & 37.5 & \\
\hline$>37$ weeks & 53 & 26.5 & \\
\hline Total & 200 & $100 \%$ & \\
\hline
\end{tabular}


IUFD was found to be more in male fetuses i.e. $61 \% \mathrm{v} / \mathrm{s}$ females fetuses $39 \%$.and more in preterm fetus as compared to term fetuses. $36 \%$ was found in fetuses less than 32 weeks and $37.5 \%$ was found in gestational age $32-36$ weeks whereas it was $26.5 \%$ in term babies.

$60 \%$ IUFD were found among fetuses weighing 2000 grams or less due to prematurity. Still birth was most common in fetuses of $1 \mathrm{Kg}$. or less $(23.60 \%)$. It was least with birth at $3.5 \mathrm{Kg}$ or more $(1.55 \%)$.

Table 3: Distribution of cases according to Causes of still birth.

\begin{tabular}{|lll|}
\hline Causes of cases & Total number & Percentage \\
\hline Abruption & 28 & 14 \\
\hline Placenta previa & 06 & 3 \\
\hline Pre eclamptic toxemia & 25 & 12.5 \\
\hline Eclampsia & 18 & 9 \\
\hline Severe anemia & 09 & 4.5 \\
\hline Rh incompatibility & 02 & 1 \\
\hline IUGR & 05 & 2.5 \\
\hline Polyhydramnios & 04 & 2 \\
\hline Post maturity & 07 & 3.5 \\
\hline Jaundice & 03 & 1.5 \\
\hline Oligohydramnios & 15 & 7.5 \\
\hline PROM & 04 & 2 \\
\hline Congenitalanamoly & 11 & 5.5 \\
\hline Cord causes & 08 & 4 \\
\hline Hepaticencephalopathy & 04 & 2 \\
\hline Hand prolapse & 05 & 2.5 \\
\hline Epilepsy & 01 & 0.5 \\
\hline $\begin{array}{l}\text { Gestational } \\
\text { hypertension }\end{array}$ & 07 & 3.5 \\
\hline Diabetes & 01 & 0.5 \\
\hline Rupture uterus & 06 & 3 \\
\hline Unidentified & 25 & 12.5 \\
\hline MSL & 06 & 3 \\
\hline Total & 200 & $100 \%$ \\
\hline
\end{tabular}

The leading reason for IUFD was abruption (14\%) followed by hypertensive toxaemia (12.5\%). Similar incidence was of the IUD whose reason could not be identified $(12.5 \%)$. Other reasons were eclampsia $(9 \%)$, oligohydramnios $(7.5 \%)$, congenital anomalies (5.5\%), severe anaemia (4.5), cord abnormalities (4\%), gestational hypertension (3.5\%), MSL (3\%) post maturity $(3.5 \%)$, ruptured uterus $(3 \%)$, placenta previa (3\%) IUGR $(2.5 \%)$, hand prolapsed $(2.5 \%)$, polyhydramnios $(2 \%)$, PROM (2\%), hepatic encephalopathy (2\%), jaundice (1.5\%), Rh incompatibility (1\%), epilepsy (0.5\%), diabetes $(0.5 \%)$

The termination of pregnancy was attempted by various methods but mainly by use of 2 drugs. 59 cases were induced with dinoprostone, 59 cases with misoprostol, 34 underwent operative intervention and 48 were augmented with oxytocin drip.
Mean induction delivery interval of misoprostol was found to be $9.64 \mathrm{hrs}$ and mean induction delivery interval of dinoprostone was found to be $12.63 \mathrm{hrs}$.

The induction delivery interval was more in primigravida as compared to multigravida in both the groups. The mean interval in term pts was less as compared to preterm pts in both the groups thus both are more effective in term patients. $^{2}$ deaths occurred due to hepatic encephalopathy and eclampsia.

The indication for operative intervention was previous 1 section, previous 2 section rupture uterus hand prolapse, placenta previa, oligohydramnios.

Table 4: Distribution of cases according to method of induction and delivery.

\begin{tabular}{|lll|}
\hline Method & Total number & Percentage \\
\hline Dinoprostone & 59 & 29.5 \\
\hline Misoprostol & 59 & 29.5 \\
\hline Pitocin & 48 & 24 \\
\hline Operative & 34 & 17 \\
\hline Total & 200 & $100 \%$ \\
\hline
\end{tabular}

Table 5: Induction delivery interval.

\begin{tabular}{|lll|}
\hline $\begin{array}{l}\text { Method of } \\
\text { termination }\end{array}$ & $\begin{array}{l}\text { Mean induction } \\
\text { delivery interval }\end{array}$ & $\begin{array}{l}\text { Standard } \\
\text { deviation }\end{array}$ \\
\hline Dianoprostone & $12.63 \mathrm{hrs}$ & 8.223 \\
\hline Misoprostol & $9.64 \mathrm{hrs}$ & 4.224 \\
\hline
\end{tabular}

Table 6: Induction delivery interval according to gravidity and gestational age.

\begin{tabular}{|llll|}
\hline Gravidity & $\begin{array}{l}\text { Mean } \\
\text { induction } \\
\text { delivery } \\
\text { interval } \\
\text { (Misoprostol) }\end{array}$ & $\begin{array}{l}\text { Mean } \\
\text { induction } \\
\text { delivery } \\
\text { interval } \\
\text { (Dinoprostone) }\end{array}$ & $\begin{array}{l}\text { P } \\
\text { value }\end{array}$ \\
\hline Primigravida & $9.8 \mathrm{hrs}$ & $14.15 \mathrm{hrs}$ & \multirow{2}{*}{.005} \\
\hline Multigravida & $9.28 \mathrm{hrs}$ & $9.42 \mathrm{hrs}$ & \\
\hline Gestational age & & & \multirow{2}{*}{.561} \\
\hline Preterm & $9.6 \mathrm{hrs}$ & $12.75 \mathrm{hrs}$ & \\
\hline Term & $8.33 \mathrm{hrs}$ & $12.33 \mathrm{hrs}$ & \\
\hline
\end{tabular}

\section{DISCUSSION}

Incidence of IUFD at our centre was found to be 50 per 1000 deliveries which is in accordance to study conducted by ChoudharyAnjali et $\mathrm{al}^{6}$ which revealed prevalence as 49 per 1000 live births. In a Retrospective study by SinghNeetu et $\mathrm{al}^{7}$ incidence of IUFD reported was 40 per 1000 . The reason for high incidence is that our centre is a Tertiary referral centre.

Various causes of IUFD need to be identified in order to prevent them and reduce the burden. 
In our study that maximum number of still birth occurred between the age group of 21 to 25 years $(51 \%) .2^{\text {nd }}$ in the age group 26-29 (14.5\%). This is in accordance with the study by Singh neetu7 et al in which the maximum IUD were in the age group 21-25 (45.71\%) followed by age group 26-30 (36.19\%). Similar results were found in the study by Choudhary A et $\mathrm{al}^{6}$ also. Pregnancy in extremes of age group and obesity in reproductive age group is uncommon in our setup. Out of total 200 cases 173 were unbooked as compared to 27 booked cases showing the importance of proper antenatal care so that the high risk patients could be identified earlier and timely referred so that IUFD can be prevented. Maximum number of IUFD occurred in primi $(44.5 \%)$, followed by second gravida $(37.5 \%) 3^{\text {rd }}$ gravida $10 \%$ and in $4^{\text {th }}$ and $5^{\text {th }}$ gravida it was $7 \%$ respectively. In the study by neetu singh et $\mathrm{al}^{7}$ it was found that the incidence was maximum in primigravida (25\%) followed in order $17 \%, 18 \%$ and $24 \%$ in grandmultiparity according to increase in parity.

We included only the antepartum intrauterine deaths in which the leading reason for IUD was abruption (14\%) followed by Hypertensive toxemia (12.5\%). Similar incidence was of the IUFD whose reason could not be identified Idiopathic (12.5\%). Other maternal factors were eclampsia, oligohydramnios, severe anaemia, gestational hypertension, post maturity, rupture uterus, PROM, polyhydramnios, hepatic encephalopathy, jaundice, RH incompatibility, epilepsy, diabetes.

In study by Choudhary $\mathrm{A}$ et $\mathrm{al}^{6}$ similar findings were there, hypertensive disorder to be complicating $28.7 \%$ pregnancies and Diabetis in $4.2 \%$ women. A total of $17.2 \%$ cases presented with Ante partum hemorrhage out of which $3.9 \%$ were placenta previa, and $11.7 \%$ placental abruption. Mild anemia was found in $19.4 \%$ cases, moderate in $6.3 \%$ cases and $15.9 \%$ were severely anemic. There was one case of road traffic accident. Severe IUGR was found to be responsible for the death of $8.5 \%$ babies, $11.5 \%$ fetuses had congenital anomalies. Maternal infections were found to be complicating eight pregnancies out of which there were two cases of jaundice (infective hepatitis) five cases of clinically proven malaria and one case of pneumonia. There were $19.5 \%$ women where no causative factor was found for intrauterine fetal demise. Singh Neetu et $\mathrm{al}^{7}$ found $33 \%$ unexplained fetal deaths in their study of 296 cases of IUFD

Over the years the causative factors responsible for IUFD have changed. There was an observation that not only the incidence is reducing in developed countries, but the patterns of etiologies are also changing syphilis and other infections are no longer significant. In many studies hypertensive disorders complicated by abruption as found to be the main cause. Among the fetal causes, major congenital anomalies accounted for $5.5 \%$ cases. The main congenital malformations we found were anecephaly, congenital heart disease, renal agenesis, hydrocephalous multiple anomalies in placental causes abruption, placenta previa and cord abnormalities were important contributing factors. The IUFD in our series was more in male fetuses $61 \%$ than females' fetuses. In the study by SinghNeetu ${ }^{7}$ et al it was $54 \%$ in males and $46 \%$ in females. Whereas in study by Choudhary A et al $^{6}$ there were 58 male babies v/s 47 female babies. 60\% IUFD were found among fetuses weighing 2000 grams or less. It is obvious that prematurity is contributing factor. In developed countries maternal and fetal outcomes have been improved due to early arrival of the patient and timely intervention.

After the diagnosis of intrauterine death the patient may choose to wait for spontaneous labour which is not common and it becomes necessary to terminate the pregnancy. In our study 59 pts were induced with dinoprostone, 59 pts were induced with misoprostol, 34 underwent operative intervention and 48 were augmented with oxytocin drip.

Many clinical trials have demonstrated that misoprostol is effective for induction of labour at term, including prelabour rupture of membranes. In our study mean induction delivery interval of misoprostol was found to be $9.64 \mathrm{hrs}$ and mean induction delivery interval of dinoprostone was found to be $12.63 \mathrm{hrs}$.

Various methods of induction of labour following IUFD have been tried and studied and most of the studies compared between combined method (mifepristone and misoprostol) and misoprostol only. No study has been undertaken to compare the role of dinoprostone gel vs. misoprostol in induction of labour in a case of IUFD however there are various randomized studies, which compared vaginal misoprostol with dinoprostone for induction of labour at term with living fetus. In those studies the incidence of vaginal delivery within $24 \mathrm{~h}$ of induction was found higher in the misoprostol group. In a study by Titol Biswaset $\mathrm{al}^{8}$ the mean induction delivery interval in misoprostol was found to be $8.13 \mathrm{hrs}$ whereas in dinoprostone was found to be $14.32 \mathrm{hrs}$.

The Misoprostol was found to be more efficacious than dinoprostone in terms of induction delivery interval and the amount of doses required and less need of Oxytocin augmentation. In a study by Kriplani A et $\mathrm{al}^{9}$ the efficacy at term induction delivery, interval was shorter in misoprostol; $12.8+/-6.4 \mathrm{~h}$ versus $18.53+/-8.5 \mathrm{~h}$ in dinoprostone. A 2010 Cochrane review10 concluded that vaginal misoprostol was also superior to other induction agents (vaginal prostaglandin, intracervical prostaglandin, and oxytocin), with less epidural use and fewer failures to achieve vaginal delivery within 24 hours, but more tachysystole with FHR changes. The indication for operative intervention was previous 1 section, previous 2 section rupture uterus hand prolapsed, placenta previa, oligohydramnios. The induction delivery interval was more in primigravida as compared to multigravida. In both the groups misoprostol was more effective in multigravida. In a study by Batool et al ${ }^{11}$ oral misoprostol 
is effective for induction of labour in both primigravida and multigravidas. Induction to delivery was less than 18 hours in multigravida and it was more than 18 hours in primigravida. The study indicates that the mean induction delivery interval of misoprostol is less in term patients (8.33 hrs) as compared to preterm patients (9.6 hrs). Similiarly in dinoprostone the mean interval in term pts was less (12.33 hrs) as compared to preterm pts (12.75 hrs). Thus both are more effective in term patients.

\section{CONCLUSIONS}

The main aim of the study was to study the various risk factors and causes of intrauterine death to reduce the incidence. It can be concluded from the present study that Socio- demographic factors need to be considered as predisposing factor for prenatal deaths. Literacy, teenage pregnancies, unregulated reproduction, low socioeconomic states, poor nutrition, lack of health education and antenatal care all conspire against the women's health and predispose her to IUFD. Many of the causes of intrauterine death found out to be preventable like abruption hypertensive disorders which can be avoided by proper antenatal care. The use of folic can prevent neural tube defects. Training of dais can help in early diagnosing high risk pregnancies so that they can be timely referred.

After diagnosing intrauterine dead baby the method of termination is chosen accordingly. The labour can be augmented by pitocin or induction can be done by prostaglandins. In the study it was observed that misoprostol is more effective in induction of intrauterine death as compared to dinoprostone in terms of induction delivery interval and cost effectiveness.

Maternal and child health services are to be evaluated and improved. Health agencies, public health personnel social workers to \& traditional birth attendants should be properly trained for proper antenatal care and timely diagnosis of intrauterine death.

Funding: No funding sources Conflict of interest: None declared

Ethical approval: The study was approved by the Institutional Ethics Committee

\section{REFERENCES}

1. Revision of the procedures for coding cause of fetal death ICD-10 Mortality manual 2013. Available at http://www.who.int/reproductivehealth/topics/matern al_perinatalet/stillbirth/en. Accessed on 25 February 2016.

2. ACOG Issues New Guidelines on Managing Stillbirths. Available at http://www.acog.org/AboutACOG/News-Room/News-Releases/2009/ACOGIssues-New-Guidelines-on-Managing-Stillbirths. Accessed on 25 February 2016.

3. National vital statistics reports. Volume 60, Number 8 August 28, 2012. Fetal and Perinatal Mortality, United States, 2006.

4. Estimates of mortality indicators-Census of India website-vital statistics. Chapter 4, Pg 81, statement 51, 2010.

5. Censusindia. Available at. Censusindia.gov.in/vital_statistics/srs/Chap_4_2010.pdf. Accessed on 25 February 2016.

6. Choudhary A, Gupta V. Epidemiology of intrauterine fetal deaths: a study in tertiary referral centre in Uttarakhand. IOSR J Dent Med Sci. 2014;13(3):3-6.

7. Singh N, Pandey K, Gupta N, Arya AK, Pratap C, Naik R. A retrospective study of 296 cases of intra uterine fetal deaths at a tertiary care centre. Int $\mathrm{J}$ Reprod Contracept Obstet Gynecol. 2013;2(2):141-6.

8. Biswas T. Misoprostol (PGE1) versus dinoprostone gel (PGE2) in induction of labour in late intra uterine fetal death with unfavourable cervix: a prospective comparative study. Int J Reprod Contracept Obstet Gynecol. 2015;4(1):35-7.

9. Agrawal N, Gupta A, Kriplani A, Bhatia N. Six hourly vaginal misoprostol versus intracervical dinoprostone for cervical ripening and labor induction. J Obstetr Gynaecol Res. 2003;29(3):14751.

10. Hofmeyr GJ, Gülmezoglu AM, Pileggi C. Vaginal misoprostol for cervical ripening and induction of labour. Cochrane Database of Systematic Reviews 2010;10:CD000941.

11. Batool S. Comparison of oral misoprostol for induction of labour in primigravidas and multigravidas. Asian J Pharm Clin Res. 2013;6(2).

Cite this article as: Dave A, Patidar R, Goyal S, Dave A. Intrauterine fetal demise-a tragic event: a study of its epidemiology, causes and methods of induction. Int J Reprod Contracept Obstet Gynecol 2016;5:1316-21. 